\title{
Impact of colchicine on morphology of different developmental stages of Lymnaea stagnalis \\ Payal Mahobiya
}

\author{
Department of Zoology \\ Dr. Harisingh Gour University, SAGAR M.P. \\ Email.1607payal@gmail.com
}

Received : 18.03.2020; Accepted : 22.04.2020

\begin{abstract}
The molluscicidal effect of colchicine was evaluated against various stages of the freshwater snail Lymnaea stagnalis, immature, young mature and adults. Calculated values of lethal concentrations $\left(\mathrm{LC}_{50}\right.$ and $\left.\mathrm{LC}_{100}\right)$ showed colchicine as toxic against eggs, immature and adults. Results revealed that colchicine could be used to control harmful snails, as it significantly controls reproduction of these snails. The colchicine reduces fecundity, prolongs hatchability period and reduces survival of the newly hatched snails in a snail population, when exposed to a concentration lower than $\mathrm{LC}_{50}$. So, this investigation was made to know more about the intoxication of alkaloids of colchicines on the mortality and survivality of hatched young snail of pest snail.

Figures : 02

References : 12

Tables : 02

KEY WORDS : Colchicine, Developmental stages, Lethal concentration, Lymnaea stagnalis.
\end{abstract}

\section{Introduction}

Snails are of great importance from viewpoint of economy. They are distributed worldwide. They are the source of animal protein and act as intermediate hosts of trematode parasites which are the causative agent of helminthes diseases. Like all other animals in the aquatic ecosystem, the abundance and distribution of fresh water snails depend on several ecological and water physicochemical parameters.

Lymnaea stagnalis are freshwater snails. These common pond snails are widely used in embryological studies $^{6}$. Till date extensive studies have been carried out throughout the world on the embryology and different developmental stages of marine and freshwater snails.

Series of incidents take place in the develpoment and maturation of snails viz., mating, hatching, cleavage, gastrula, blastula, post gastrular changes, organogenesis and morphogenesis, formation of trochophore larvae, formation of veligar larvae, teratogenesis, emergence of the young snails and their growth till adulthood. Breeding pattern was observed in different drug treatment in the snails. The egg type of Lymnaea acuminata was described as an iso-lecithal and the cleavage as spirally holoblastic type ${ }^{7}$.

The embryological and cytological studies conducted over the last 20 years suggest the existence of several different types of embryonic determination in the course of the pond snail development. This investigation was carried out to know more about the effect of colchicine on mortality and reproductive performance of Lymnaea stagnalis.

\section{Materials and Methods}

\section{Snail Collection}

The adult snail Lymnaea stagnalis were collected from the Pond of Botany Department, Dr Harisingh Gour Universirty, Sagar, M.P. and Sagar Lake, Madhya Pradesh. The collected snails were acclimatized in glass aquarium containing dechlorinated tap water in laboratory condition for $72 \mathrm{~h}$ and used as the experimental animals ${ }^{10}$.

\section{Antitubulin Drug}

Colchicine is a toxic natural product and secondary metabolite and inhibits microtubule polymerization by binding to tubulin, tubulin one of the main constituents of microtubules. Availability of tubulin is essential to mitosis and therefore colchicine effectively functions as a "mitotic poison" or spindle poison. The antitubulin drugs of analytic grade of Colchicine procured from CDH company.

\section{Batch Experiment}

To study the effect of colchicine, snails in dechlorinated water were exposed to the sub-lethal concentration antitubiline drugs colchicine. Young 
TABLE-1: Data on Toxicity of Colchicine on Egg Masses of Lymnaea stagnalis

\begin{tabular}{|l|c|c|c|c|c|}
\hline S. No. & $\begin{array}{c}\text { Name of the } \\
\text { antitubulin } \\
\text { drug }\end{array}$ & $\begin{array}{c}\text { Concentration } \\
\text { of the antitubulin } \\
\text { drug }\end{array}$ & $\begin{array}{c}\text { Duration } \\
\text { (hrs.) }\end{array}$ & $\begin{array}{c}\text { Mortality } \\
\text { (\%) }\end{array}$ & $\begin{array}{c}\text { Lethal } \\
\text { conc. } \\
\text { value }\end{array}$ \\
\hline 1. & & $0.12 \%$ & 72 & $100 \%$ & LC $_{100}$ \\
2. & Colchicine & $0.06 \%$ & 72 & $50 \%$ & $\mathrm{LC}_{50}$ \\
3. & & $0.03 \%$ & 72 & $\mathrm{Nil}$ & $\mathrm{LC}_{0}$ \\
4. & & $0.02 \%$ & 72 & Nil & Sublethal \\
concentration
\end{tabular}

$0.02 \%$ concentration of colchicine was considered as sublethal concentration value.

Lymnaea stagnalis hatched from egg masses were used for the experimental purpose to different concentrations of antitubulin drug through media. Each egg mass contained 50 egg capsules and group was in triplicate and data were summarized in Table No.1 and Fig. No.1. Probit analysis method ${ }^{1}$ was adopted to calculate $\mathrm{LC}_{50}$ of colchicine. Since it is difficult to identify a particular spawn, capsule containing eggs from each treated group were incubated at $30^{\circ} \mathrm{C}$ in covered petridishes containing the same concentration as given to adult snails. The development of embryos was observed under a binocular microscope at regular interval upto their hatching. Percent hatching was studied only with eggs laid after the $24 \mathrm{~h}$ exposure periods. Dead embryo was removed to avoid any contamination. Survival of young snails was observed upto $72 \mathrm{~h}$.

Experiments were Done on the Different Developmental Stages of Lymnaea spp. Selected in the Present Investigation are as Follows:

1. Cleavage.

2. Blastula.

3. Gastrula.

4. Post gastrular changes e.g. Morphogenesis and Organogenesis.

5. Formation of Trochophore larvae.

6. Number of Trochophore transformed into veligar larvae.

7. Torsion in veligar larvae.

8. Metamorphosis of veligar into young snails.

9. Hatching of young snails from their respective egg capsules.

10. Following stages were observed by Phase Contrast Optics Microscope.

\section{Results}

The results of the present study revealed that the antitubiline drugs showed positive effects on reduction of snail population, data are summarized in Table No. 2 .

After 2-3 days of incubation, the developing embryos attained the trochophore stage. At the beginning of the 4th day of incubation, embryos became slightly elongated, curved foot muscle and shell gland were developed through the extension of velum and the embryos turned into the early veliger. At the beginning of the seventh day, the miniature snail possessed all the structures found in a newly hatched individual.

Snail Lymnaea stagnalis breeds around the year and lays eggs on the lower surface of the aquatic vegetation. It releases their eggs in two or three hours of morning time. The eggs were laid in succession. The eggs were gummy and sticky in fresh condition.

In the present study, when eggs were fertilized, different developmental stages were started under favorable conditions and no sterile eggs were observed in control groups. In the present investigation, the variable number of egg masses or various size egg capsules of Lymnaea stagnalis were obtained, in which most of them did not show any progressive development.

The different developmental stages of Lymnaea stagnalis in the control group and treated group are shown in Fig. 2 ( $\mathrm{A}$ to $\mathrm{H}$ ) respectively. Fresh egg masses laid by the snails of $F_{o}$ generation were introduced to different concentrations of antitubilin drugs and data were recorded.

\section{Cleavage}

Spiral cleavage observed in the present investigation. Cleavage begins about $2^{1 / 2}$ to 3 hours after the egg masses were laid in the control group of Lymnaea but it started after $5 \pm 2$ hours after treatment with colchicine 


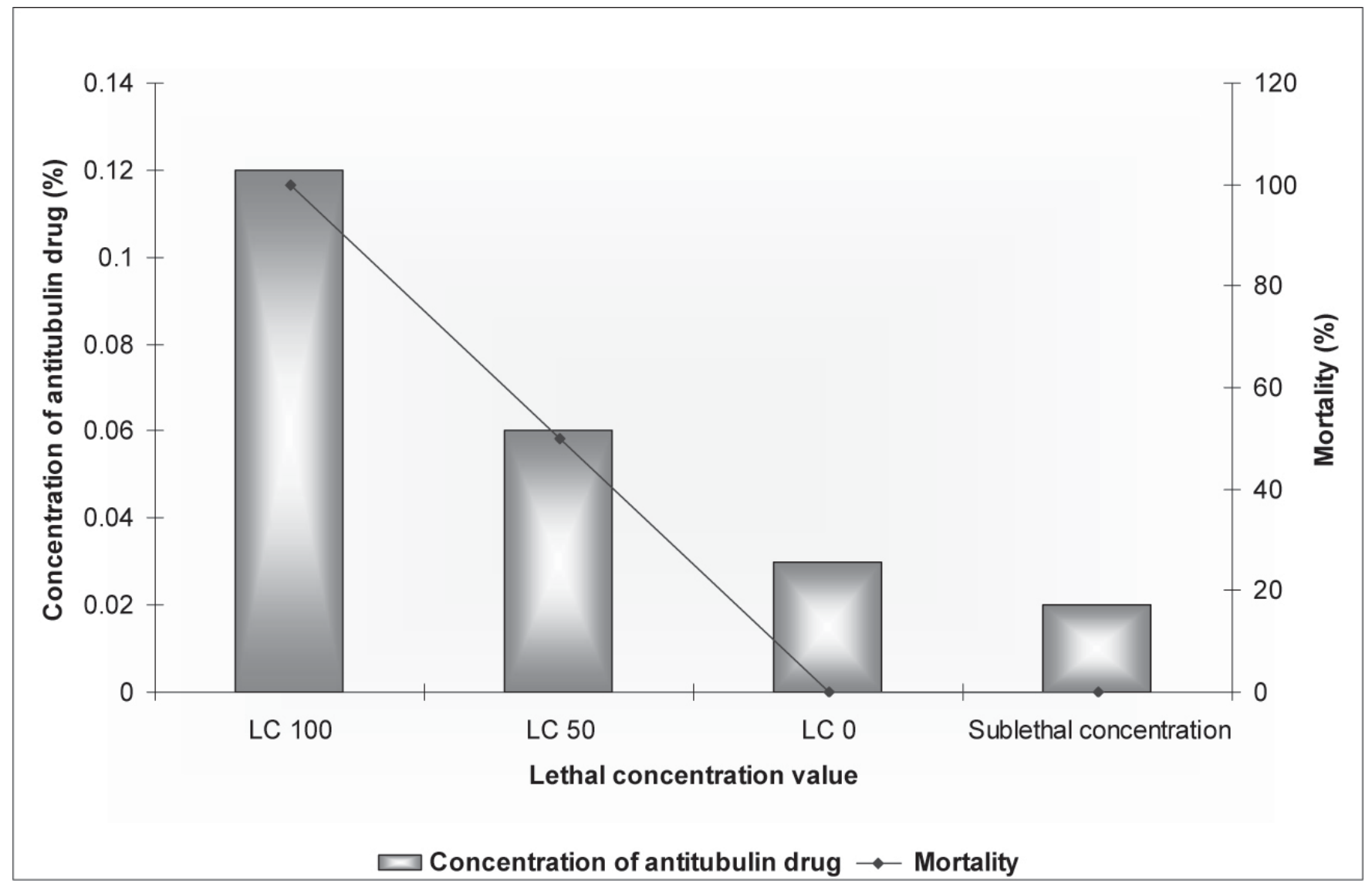

Fig. 1 : Showing Lethal Concentration Values and Mortality \% Rate in Egg Masses of Lymnaea stagnalis after Treatment with Colchicine

in Lymnaea stagnalis. The dose and duration of treatment dependent increase in the duration of cleavage has been observed in the experimental snails of Lymnaea stagnalis

\section{Blastula}

In the present investigation in Lymnaea spp., it was observed that blastula period was increased in colchicine treatment. However, mortality during blastula stage ranged from 0.5 to 1.0 percent.

\section{Gastrula}

The gastrulation period increased by $4: 2$ hours in Docetaxel and 5:2 hours in colchicine treatment. This stage was found to be more susceptible as mortality occurred in the later gastrula stages.

\section{Post gastrular changes}

After gastrulation three germinal layers were formed and organogenesis and morphogenesis were started in control as well as in experimental snails but the duration was somewhat prolonged in experimental snails and was found to be dependent on dose and duration of treatment in comparison to the control groups.

\section{Organogenesis and Morphogenesis}

After formation of three germinal layers organogenesis and morphogenesis took place. The organs formed by three germinal layers are

\section{Formation of trochophore larvae}

After organogenesis and morphogenesis specific two larvae have been formed. These two larval forms were trochophore and veligar larvae during development of these experimental snails viz. Lymnaea. The trochophore larval period was prolonged by $4 \pm 2$ hours in colchicines treatment. High percentage of mortality was observed during this stage.

\section{Formation of veligar larvae}

In the present investigation in Lymnaea the veligar larval period was increased by $6 \pm 2$ hours in colchicine treatment. Mortality during this period was high but less in comparison to trochophore larval stage.

\section{Teratogenesis}

Egg masses treated with different concentrations of colchicine showed some cyclocephalic embryos in Lymnaea spp. Such embryos showed the characteristic malformation. It was concluded that the effect of the treatment showed the suppression of the differentiation of the ectoderm being most pronounced at the animal pole and decreasing with the increasing distance in the 
CONTROL GROUP
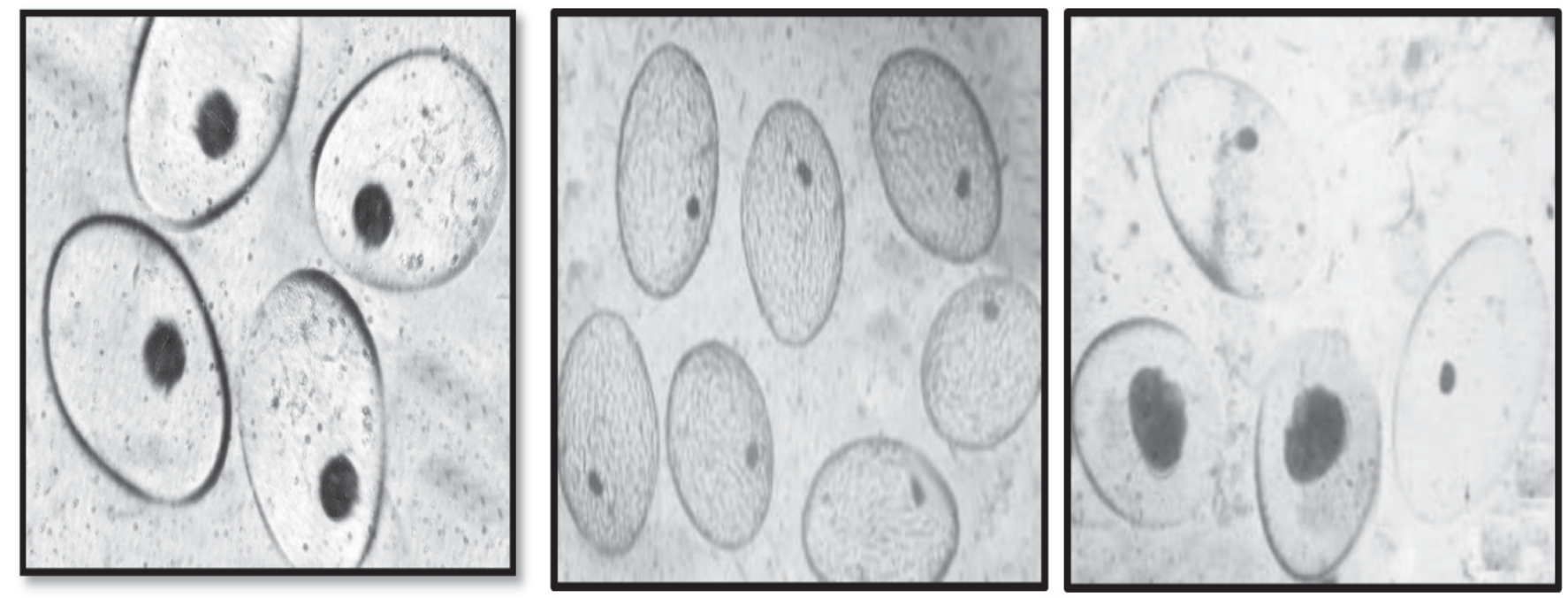

A. Cleavage stage Stage of Control and treated group
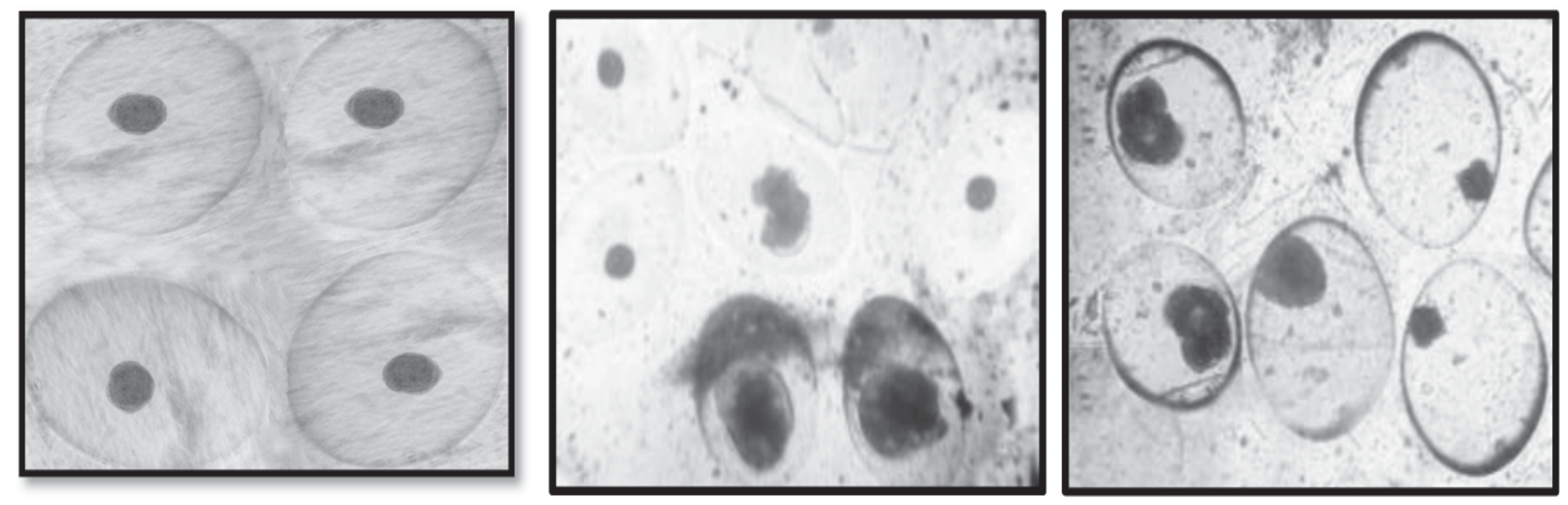

B. Blastula stage of control and treated group
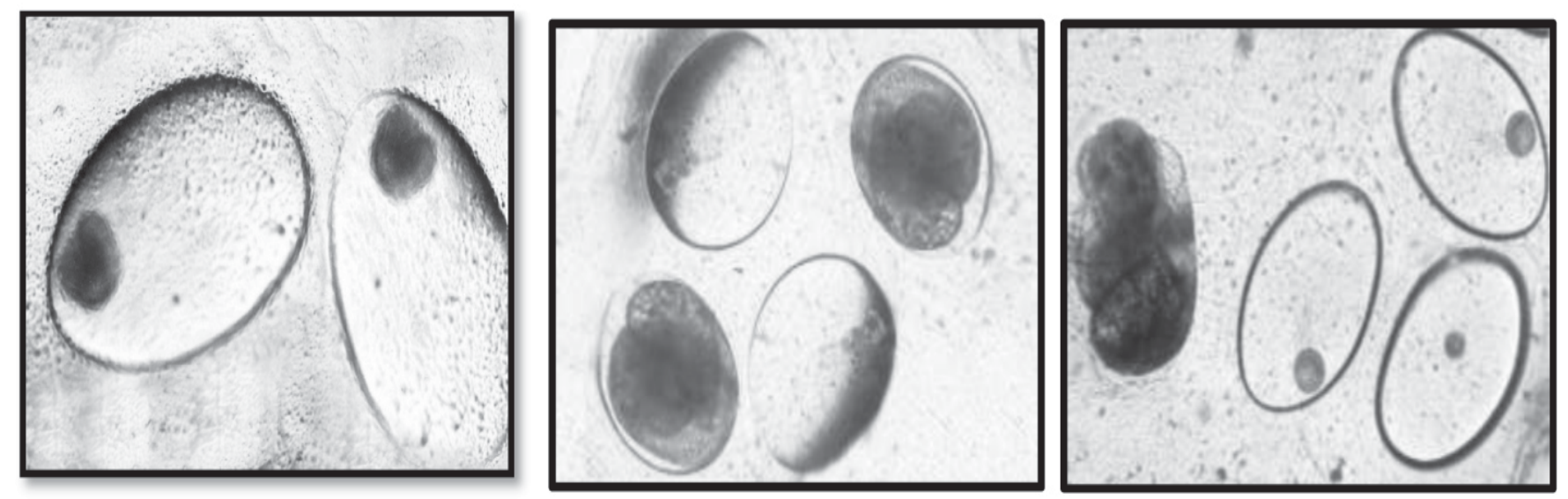

C. Gastrula stage of control and treated group 


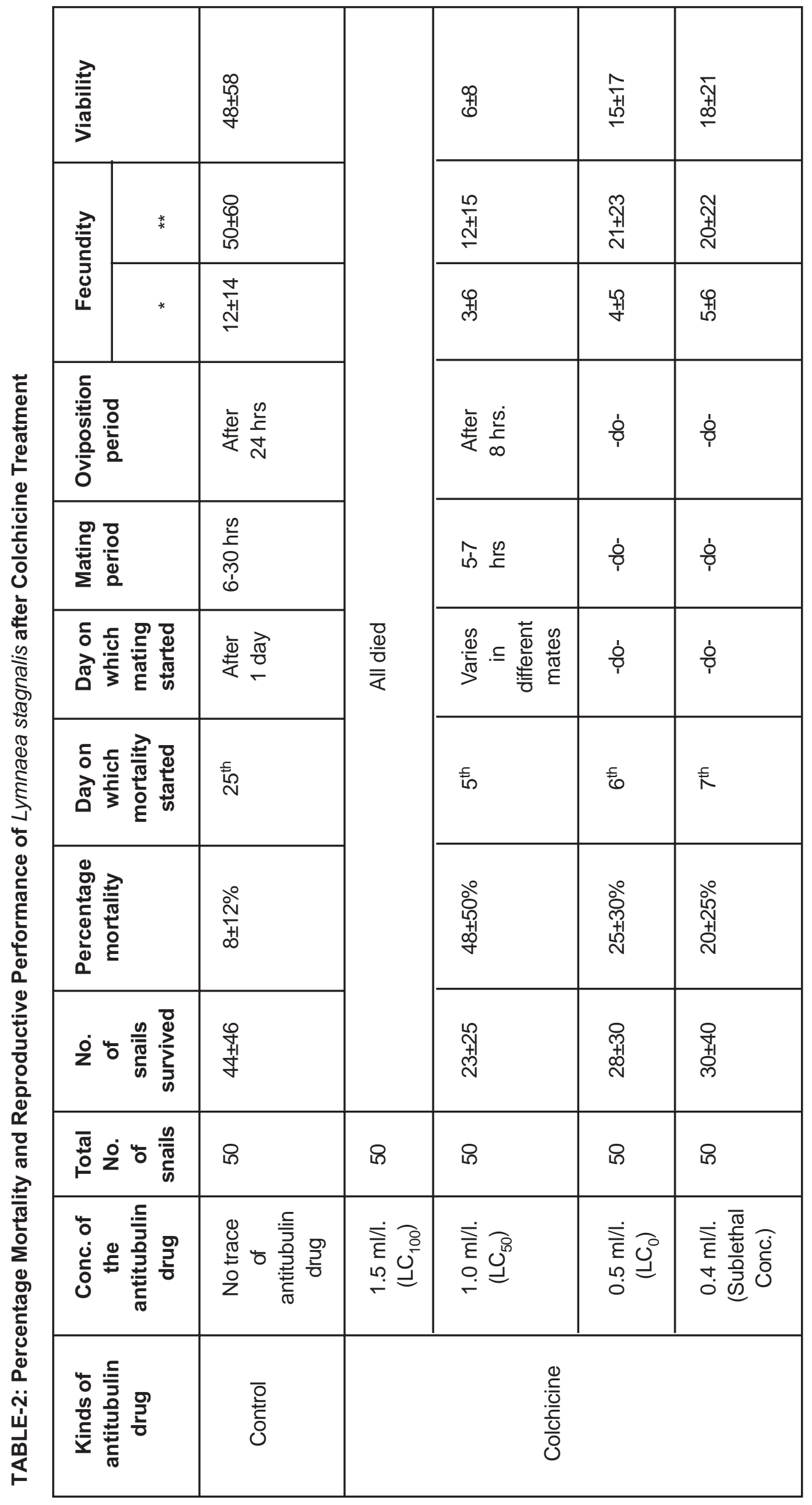



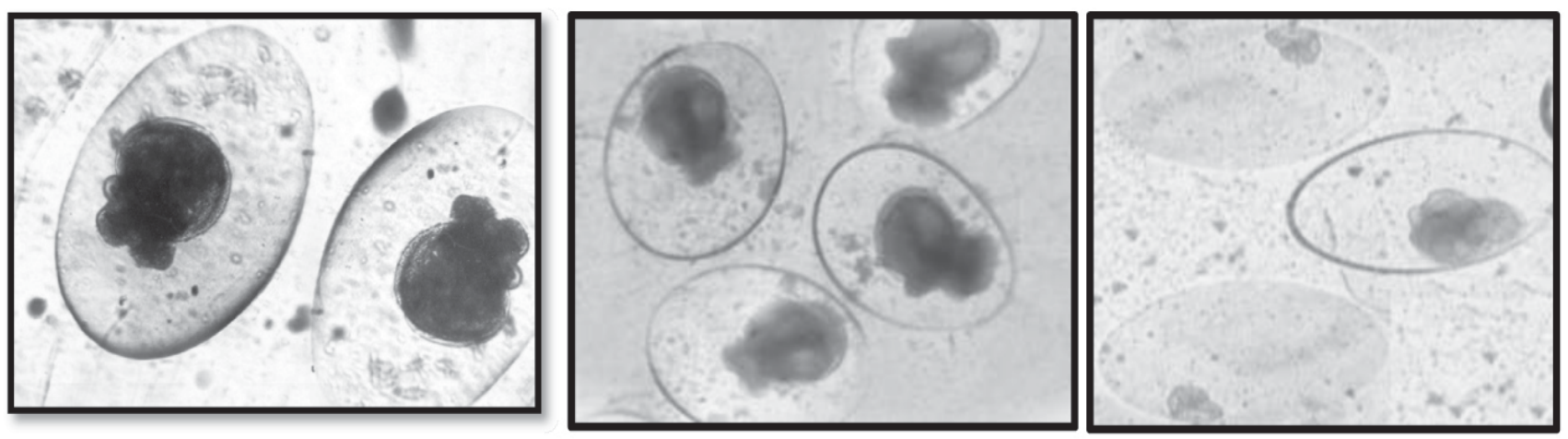

D. Trochophore larval stage of Control and treated group
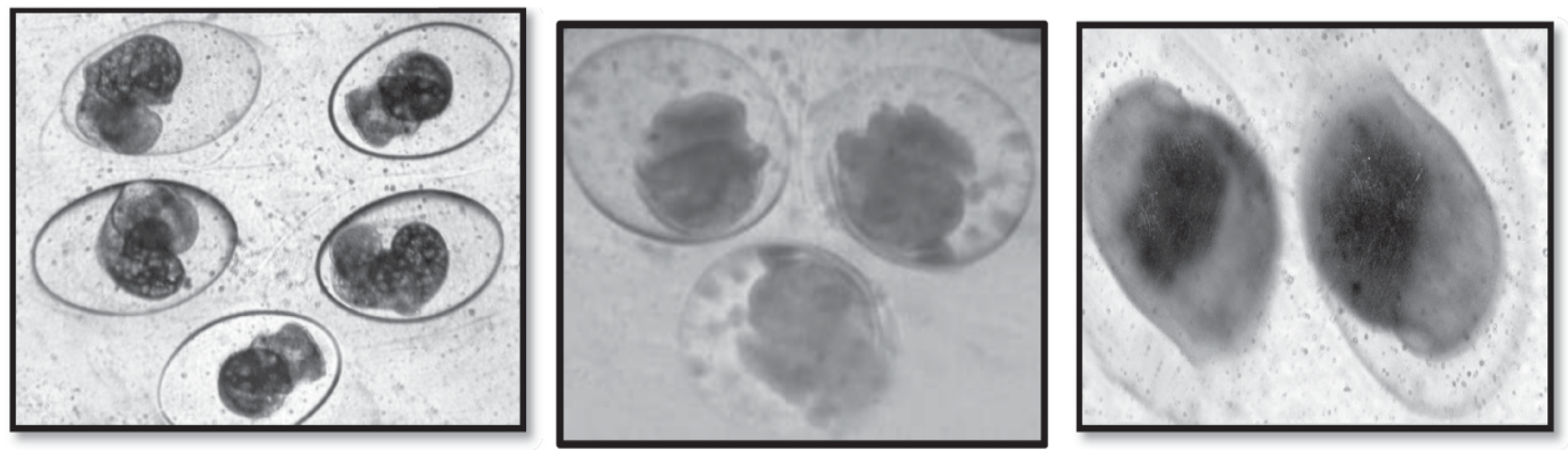

E. Veliger larval stageof Control and treated group
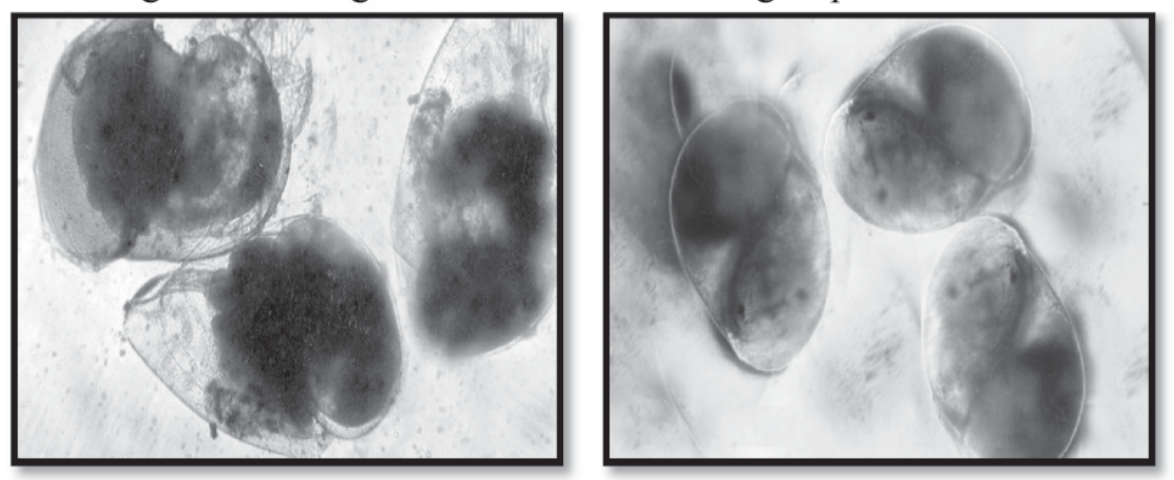

F. Hatching stage of control group

G. Hatching young snail of control group
H. Hatched young snail of control group

Fig. 2 : Egg capsules of Lymnaea stagnails showing different developmental stages of control groups and colchicine treated groups $(\mathrm{A}-\mathrm{H})$

pole. In the present investigation, the archentron found in more or less abnormal way and part of the presumptive endoderm remaining at the surface of egg masses treated with colchicine.

\section{Emergence of the young snails and their growth till adulthood}

Though after full development in treated groups, some young larvae were weakened so that they were unable to break the egg capsule and died due to starvation and that was the potent cause of the higher percentage of mortality during hatching of young snails.

It was observed that the young snails hatched from the treated egg masses showed much delay in attaining maturity in comparison to control groups. They were mostly found attached on the walls of the container and were apathetic towards feed. They had very thinner shells. Tentacles were short. Movement was slow. They were smaller in size. Life span was very short with decreased 
rate of fecundity.

\section{Discussion}

The present investigation revealed that the antitubiline drug colchicines used during experiment showed great sublethal concentration for Lymnaea stagnalis snail. Colchicine affect the embryological development of snail and control their growth and could be used as molluscicide drug to control snail population. In the current study, various developmental stages of snail of eggs and embryo studies are similar to report that the embryonic developmental ecology of freshwater snail Lymnaea acuminate ${ }^{7}$. The data obtained from their study suggest that $L$. acimunata has wide range of ecological factors which indicate their wide range of survibality. It has reported the Molluscicidal effect of nicotinanilide and its intermediate compounds against a freshwater snail Lymnaea luteola. Workers ${ }^{2,3}$ used niclosamide as molluscicide for induction of teratogenesis of freshwater Snail (Biomphalaria alexandrina) and conducted to study the molluscicidal effect of plant extract for population control of snail. The synthetics molluscicides caused a significant reduction in the fecundity, hatchability and survival of the young snails studied earlier and Docetaxel caused the significantly control the population of Lymnaea stagnalis observed and paclitaxel was more toxic than colchicine in gastrula stage $^{4,5,8}$. This has been shown to occur in simultaneous hermaphrodites as well as in organisms with separate sexes. Although accessory gland proteins affect the investment of resources in both male and female ${ }^{11}$.

\section{Conclusion}

In conclusion, colchicines reduced fecundity, percent hatchability and survival of young snail of Lymnaea stagnalis efficiently. Hence it can be used to control the population of freshwater snails. It could be concluded from the present investigation that the alkaloid used for the treatment, were able to arrest the development at any stage, in which larval stages were most susceptible suggested the larvicidal nature of the alkaloid which induces teratogenicity. The observations made, open a new avenue for future workers to establish developmental mechanism and snail culture farms. However, much more research is solicited in this line.

\section{References}

1. Finney DJ. Probit analysis. $3^{\text {rd }}$ Edn. Cambridge University Press, London.1971.

2. Hoda KS, Samia HHE, Manar AK. Induction of teratogenesis of freshwater Snail (Biomphalaria alexandrina) using the molluscicide Niclosamide.. Sci-Afric Journal of Scientific Issues, Research and Essays. 2014; 2 (6): 255-268.

3. Kushwaha VB, Singh A. Effect of Uscharin on the Reproduction of the Snail Lymnaea acuminata. World Journal of Zoology. 2010; 5 (1): 15-19.

4. Mahobiya P, Kumar A, Bhide M. Biochemical studies on the gastrula stage of a fresh water snail lymnaea acuminata after treatment with colchicine and taxol. International Journal of Recent Scientific Research. 2014; 5 (4):712-715.

5. Manekar S, Mahobiya P. Toxic effect of docetaxel and vinorelbine on protein fraction of Lymnaea stagnalis during cleavage stage. Research Journal of Life sciences, bioinformatics, pharmaceutical and chemical sciences. 2018; 4(5):396-400.

6. Muley DV. Embryology and development of freshwater prosobranch, Melania scabra. Hydrobilogia. 1978; 58 (1) : 89-92.

7. Sarker MM, Nesa B, Jahan MS. embryonic development ecology of freshwater snail Lymnaea acuminata (Lymnaeidae : Gastropoda). Pak J. Biol. Sci. 2007;10 (1): 23-31.

8. Singh V, Tiwari JVN. Effects of Synthetic and Extracts of Plant on Reproduction of Snail Lymnaea acuminata. Research Journal of Pharmaceutical, Biological and Chemical Sciences. 2012; 3(4): 705- 710.

9. Singh V, Kumar P, Singh VK, Kumar DK. Effect of abiotic factors on the molluscicidal activity of oleoresin of Zingiber officinale against the snail Lymnaea acuminate. Natural Science. 2010; 2(10):1148-1154.

10. Subbarao NV. Handbook fresh water molluscs of India. Radiant Process Pvt. Ltd. Calcutta, India. 1989.

11. Swart EM, Starkloff NM, Ypenburg S, Ellers J, van Straalen NM, Koene JM. The effect of mating on female reproduction across hermaphroditic freshwater snails. Invertebrate biology. 2019; 1-12.

12. Zhang Y, Guo YH. Study on the effect of bromoacetamide upon the development of snail eggs. Chinese journal of parasitology \& parasitic diseases. 1992; 10(4): 258-62. 